\title{
High Efficiency Novel Window Air Conditioner
}

\author{
Pradeep Bansal \\ Building Equipment Group, Energy \& Transportation Science Division \\ Oak Ridge National Laboratory \\ One Bethel Valley Road, MS-6070, Oak Ridge, TN 37831, USA \\ Email: bansalpk@ornl.gov; Phone: +1-865-576-7376; Fax: +1-865-574-9338
}

\begin{abstract}
This paper presents the results of an experimental and analytical evaluation of measures to raise the efficiency of window air conditioners (WAC). In order to achieve a higher energy efficiency ratio (EER), the original capacity of a baseline R410A unit was reduced by replacing the original compressor with a lower capacity but higher EER compressor, while all heat exchangers and the chassis from the original unit were retained. Subsequent major modifications included - replacing the alternating current fan motor with a brushless high efficiency electronically commutated motor (ECM) motor, replacing the capillary tube with a needle valve to better control the refrigerant flow and refrigerant set points, and replacing R410A with a 'drop-in' lower global warming potential (GWP) binary mixture of R32/R125 (85/15\% molar concentration). All these modifications resulted in significant enhancement in the EER of the baseline WAC. Further, an economic analysis of the new WAC revealed an encouraging payback period.
\end{abstract}

Key words: Alternative refrigerants, window air conditioner, energy efficiency, ECM, GWP

\section{INTRODUCTION}

Window air conditioners (WAC) are inexpensive and sold in large numbers internationally as alternatives to central air-conditioning (AC) systems for space cooling, supplemental cooling and for adding $\mathrm{AC}$ to existing homes or extension of homes that do not have any $\mathrm{AC}$ to improve comfort. They are particularly attractive in older buildings that lack ducted systems and in cases where a central system upgrade is first-cost prohibitive [Bansal (2015), Bansal and Shen (2015), Nogueira (2013), Winkler et al. (2013)]. According to the US Energy Information Administration (EIA) there were nearly 46.7 million WACs operating within the United States in 2009 [EIA (2009)], accounting for approximately $1.5 \%$ of the total US residential energy use or about 0.33 quads $(0.35 \mathrm{EJ})$.

This manuscript has been authored by UT-Battelle, LLC under Contract No. DE-AC05-00OR22725 with the U.S. Department of Energy. The United States Government retains and the publisher, by accepting the article for publication, acknowledges that the United States Government retains a non-exclusive, paid-up, irrevocable, world-wide license to publish or reproduce the published form of this manuscript, or allow others to do so, for United States Government purposes. The Department of Energy will provide public access to these results of federally sponsored research in accordance with the DOE Public Access Plan (http://energy.gov/downloads/doe-public-access-plan). 
WACs are available in sizes typically between 5,000 and 16,000 Btu/h (0.4-1.3 tons, or $1460-4700 \mathrm{~W}$ of cooling). A WAC is generally installed either in a window or in a framed wall opening depending on the design of the condenser side vents. When the project was initiated in 2011, the minimum required energy efficiency ratio (EER) levels for WACs were set by the US DOE standard [e-CFR - Part 430.32 (2010)] at $9.7 \mathrm{Btu} / \mathrm{Wh}$ or $2.84 \mathrm{~W} / \mathrm{W}$ (for capacity less than $10,000 \mathrm{Btu} / \mathrm{h}$ or $2.93 \mathrm{~kW}$ ) to $9.8 \mathrm{Btu} / \mathrm{Wh}$ or $2.87 \mathrm{~W} / \mathrm{W}$ (for $10,000 \mathrm{Btu} / \mathrm{h}$ or higher capacity) for most product classes. These levels were respectively raised to 10.7 and $10.8 \mathrm{Btu} / \mathrm{Wh}$ (3.14 and 3.17 W/W) from June 1, 2014 [e-CFR - Part 430.32 (2014)].

Although vapor compression refrigeration is a highly researched topic, surprisingly very little research has been devoted to simulation and energy efficiency improvement of WACs in the open literature [Goswami et al (1993), Hajidavalloo (2007), Naphon (2010), Sawant et al (2011), Chua et al. (2013), Meissner et al. (2014)], while a few studies are devoted to investigating alternative refrigerants for WACs [Devotta et al. (2005), Jabaraj et al. (2006), Bolaji (2011), Zhou and Zhang (2010), Shen and Bansal (2014)]. One efficiency enhancement option investigated in the literature [Goswami et al. (1993), Hajidavalloo (2007)] involved application of evaporative wet cooling media pads to the WAC condenser. This option was reported to reduce the power consumption of the WAC. However, it had practical limitations of media pad fouling and difficulty in maintaining sufficient moisture in the pads to sustain the evaporative cooling effect. Sawant et al (2011) sprayed dehumidified water on to media pads placed on both sides of a WAC and achieved energy savings. They also studied an alternative approach of using wicks of porous cloth where one end of the wick was immersed in dehumidified water and the other in the entering air flow stream to the condenser. Naphon (2010) found that the use of a 3row heat pipe with refrigerant R134a as the working fluid to cool the air entering the condenser of a window air conditioner led to an EER improvement.

There are several traditional design approaches that are generally applied to improve the energy efficiency of central HVAC systems, such as variable-speed compressors and advanced control systems. The benefits of these approaches are not captured well for WACs since the performance rating testing of WACs is limited to a single test point. It may, however, be noted that the novelty of the 'single point' test is that it captures the energy consumption of the unit during peak load, which is a major consideration when conserving energy for the US. Modern WACs take advantage of slinger rings mounted on their condenser fans to spray condensate 
collected from the evaporator during operation onto the condenser (the 'sling' effect) to provide some evaporative cooling of the condenser. However, other design improvements for efficiency gains in the heat exchangers, compressor, and fan motors have not been widely adopted. In addition, because of the low initial cost of WACs, typically in the $\$ 100$ to $\$ 500$ range, any added costs for design improvements must be limited so that they are not cost-prohibitive for this market.

This project to develop a high efficiency window air conditioner was initiated by the Building Technology Program (BTO) of the Department of Energy (USA), whose goal is to reduce the energy and carbon emissions used by the energy service equipment (equipment providing space heating and cooling, water heating, etc.) by $50 \%$ compared to 2010 baseline best common practice by 2030. The average lifetime of WACs is about 10 to 13 years. This fact coupled with the potential for rapid replacement of older, less efficient units, some of which have EERs as low as $5 \mathrm{Btu} / \mathrm{Wh}(1.47 \mathrm{~W} / \mathrm{W})$ means they have potential to significantly reduce the annual U.S. energy consumption [Bansal (2015)]. Therefore, improving the efficiency of window units is essential to enhancing overall residential building energy performance. Such an initiative would not only bring energy savings to the end user but would also assist in protecting the environment as a result of reduced greenhouse gas emissions worldwide.

As per the literature review, this is perhaps the first study of its kind to design and develop a high efficiency WAC with novel features. This paper discusses an experimental evaluation of a number of system design options applied to improve the energy efficiency of a WAC with base capacity of 10,000 BTU/h (or $2.93 \mathrm{~kW}$ ) and charged with R410A (mixture of R32/R125 with 70/30\% molar concentration). These included- i) ECM (electronically commutated motor) fan motor, ii) higher rated efficiency and lower rated capacity $(8,000 \mathrm{Btu} / \mathrm{h}$, or $2.3 \mathrm{~kW})$ compressor and iii) a new 'drop-in' refrigerant mixture of R32 (with 85\% molar concentration) and R125 (15\% molar concentration). This R32/R125 blend has a 34\% lower global warming potential (GWP) than R410A ( 1,377 vs. 2,079). Due to the compact size configuration and small refrigerant charge in a typical WAC (less than $1 \mathrm{~kg}$ ), the slight flammability of the 85/15 R32/R125 refrigerant mixture is less of a concern. This is an important feature in view of the environmental friendliness of future WACs. This study documents the design details of the baseline WAC, specifically the condenser fan slinger ring, and the added features in the performance improvement of the WAC. Data analysis to determine efficiency was performed 
primarily using energy balance on the refrigerant side. The paper presents the system configurations, experimental approach and methodology to develop the high efficiency WAC, the results obtained and an economic analysis along with the payback period.

\section{SYSTEM CONFIGURATION AND EXPERIMENTAL TEST FACILITY}

A WAC unit using R410A refrigerant and having a nominal rated capacity of $10,000 \mathrm{Btu} / \mathrm{h}$ $(2.93 \mathrm{~kW})$ was selected as the baseline platform for performance evaluation and efficiency enhancement. The baseline WAC had a single-speed rotary compressor, a fin-\&-tube evaporator and condenser, a capillary tube refrigerant flow control device and a single electric motor mounted on a single axis shaft to drive both the evaporator blower and the condenser fan. In addition to these basic components, the WAC had a fin-\&-tube sub-cooler submerged in a water collection pan mounted beneath the evaporator (see Fig.1). The submerged sub-cooler provides further sub-cooling (up to $10^{\circ} \mathrm{F}$ ) to the liquid refrigerant exiting the condenser. The schematic diagram of the WAC and its P-h diagram are shown in Figures 1 and 2 respectively. As noted earlier the condenser fan blade is specially configured with a "slinger" ring designed to pick up water from the water collection pan and to spray it in the air stream flowing over the condenser coil surface. The water droplets evaporate and enhance the condenser heat transfer. This feature is called the "sling" effect [LBNL (1997)]. Figures 3, 4 and 5 respectively show the single axis fan, the "slinger" and the instrumented WAC. To promote mixing of air at the condenser outlet, a 24" section of insulated duct (shown in Figure 5) was added upstream of the condenser to allow accurate measurement of exiting air temperature and relative humidity (RH). The unit was fully instrumented and mounted between the indoor and outdoor test rooms of an environmental chamber, as shown in Figure 6.

Analysis: As noted earlier, the WAC system efficiency and the evaporator and condenser heat transfer analysis was performed on the refrigerant side. With reference to Figures 1 and 2, the condenser and evaporator heat transfer rates are respectively given by;

$$
\begin{aligned}
& q_{c}=\dot{m}\left[h\left(T_{2}, P_{2}\right)-h\left(T_{3}, P_{3}\right)\right] \\
& q_{e}=\dot{m}\left[h_{1}\left(T_{1}, P_{1}\right)-h\left(P_{5}, X_{5}\right)\right]
\end{aligned}
$$


where $\mathrm{T}$ and $\mathrm{P}$ are the measured temperat

is the measured refrigerant mass

flow rate. It is worthwhile to note here that the expansion from state 4 to 5 is assumed isenthalpic, or;

With the quality at state 5 calculated as;

where $h_{f}$ and $h_{g}$ are the interpolated specific enthalpies for the liquid and gas phases respectively. The evaporator superheat and condenser sub-cooling are given by;

where $\mathrm{T}_{\text {sat }}$ is the interpolated saturation temperature at pressure $\mathrm{P}$.

The work input to the refrigerant by the compressor is-

The overall efficiency metric, Energy Efficiency Ratio (EER), of the unit is computed by;

where $\mathrm{q}_{\mathrm{e}}$ is the system capacity in Btu/h and $\mathrm{E}_{\mathrm{t}}$ is the total electrical power usage (in watts) including both the measured compressor power and the fan/blower power.
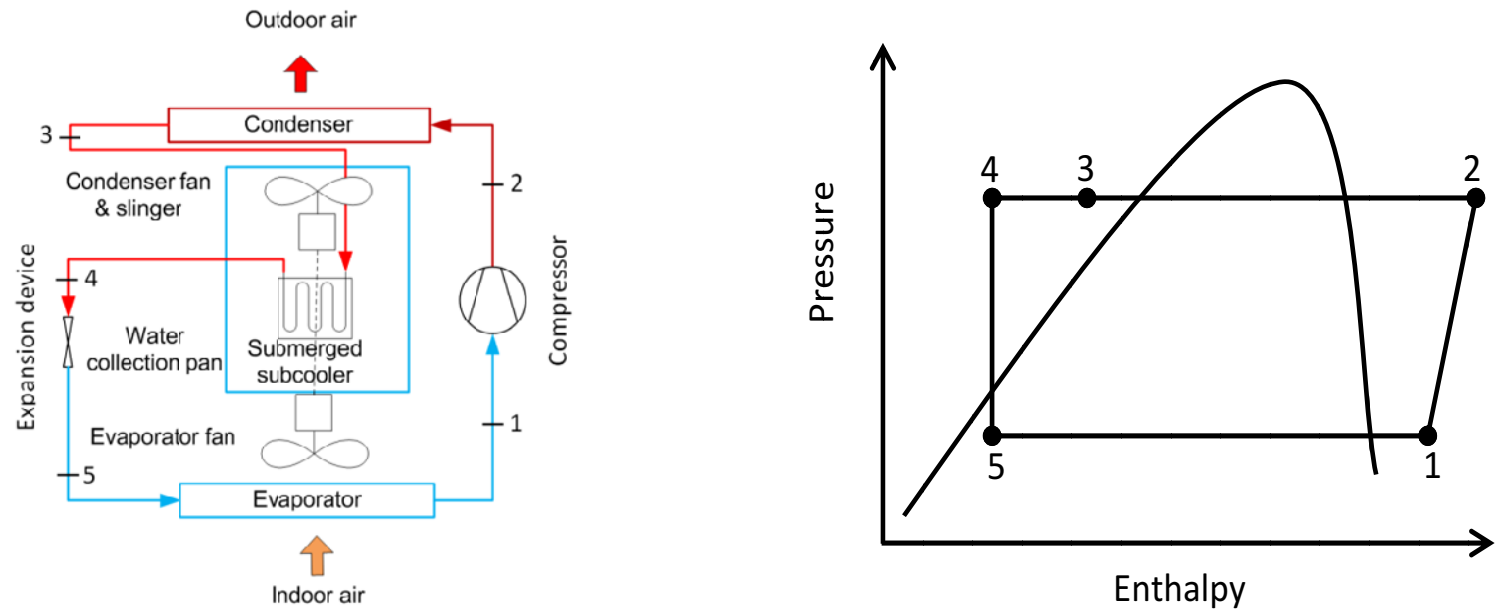
Figure 1: Schematic of Window Air Conditioner

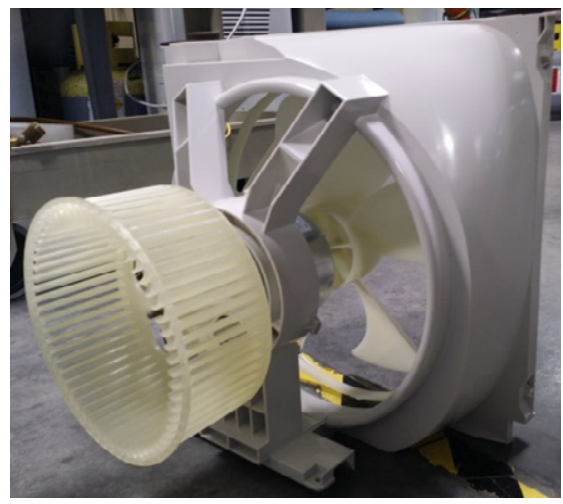

Figure 3: Single axis blower/fan

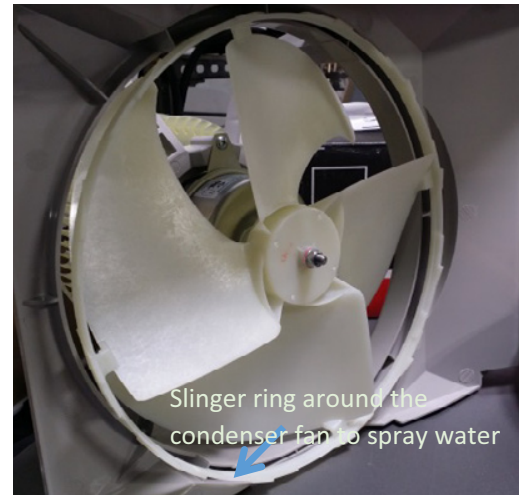

Figure 4: Slinger ring on condenser fan
Figure 2: P-h diagram of WAC

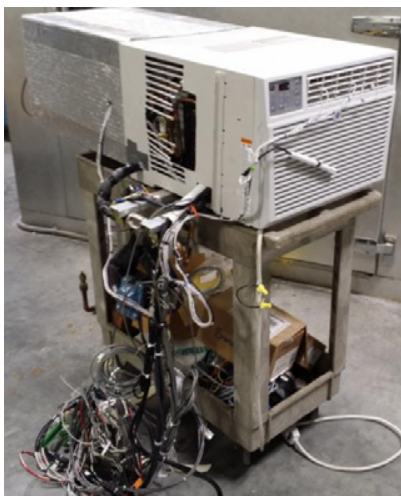

Figure 5: Instrumented WAC

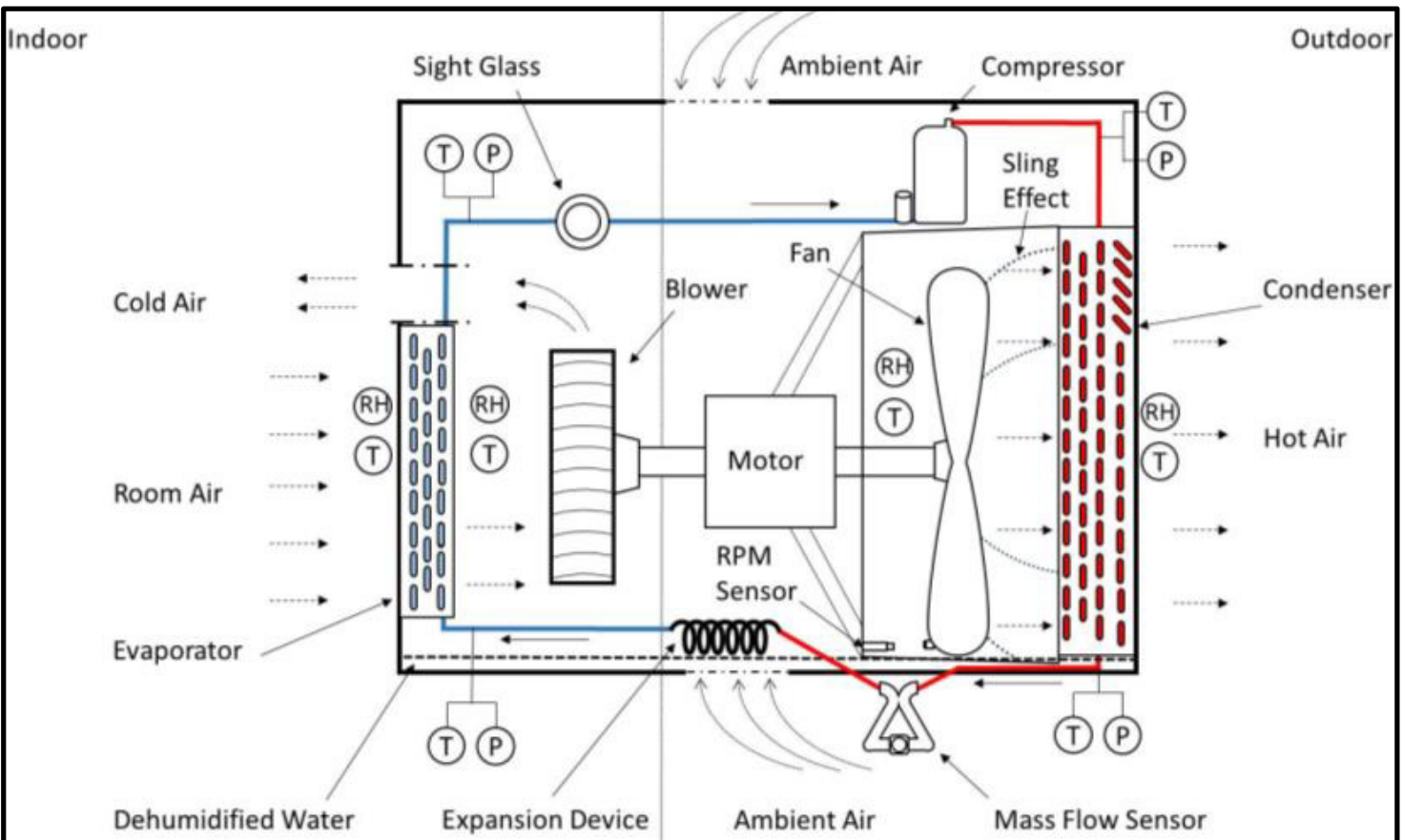

Figure 6: Schematic of the window air conditioner with instrumentation details inside an environmental chamber

\section{INSTRUMENTATION AND DATA ACQUISITION}

In order to quantify the performance of the unit, a measurement/DAS system was developed using a Campbell Scientific CR3000 data logger. The setup consists of the logger, as well as an AM16/32B multiplexer and PS100 power supply mounted in a Campbell Scientific enclosure. 
The system included integrated refrigerant lookup tables as well as a graphical user interface (GUI) on the control PC to provide real-time feedback during testing. In addition, a MathCAD based analysis tool was developed to perform a zero order uncertainty analysis in both the base measurements and the corresponding calculated quantities. The program tracks the propagation of uncertainties in the base measurements through to the final calculated quantities. (Capacity, COP, EER etc.). This unit was fully instrumented to $\log 51$ measurements including refrigerant mass flow rate using a Coriolis mass flow sensor, 3 in-line refrigerant temperatures (at suction, discharge and liquid line) using platinum resistance temperature detector (RTD) probes, 4 refrigerant side pressures using pressure transducers, 11 refrigerant side and tube wall temperatures using thermistors, 24 air-side temperatures using thermistors, 4 air side RH (relative humidity) measurements using capacitance type probes, 3 power measurements including fan, compressor, and total power; and barometric pressure. Figure 7 shows the GUI developed for this project, displaying pertinent measured and calculated quantities updated every $10 \mathrm{~s}$.

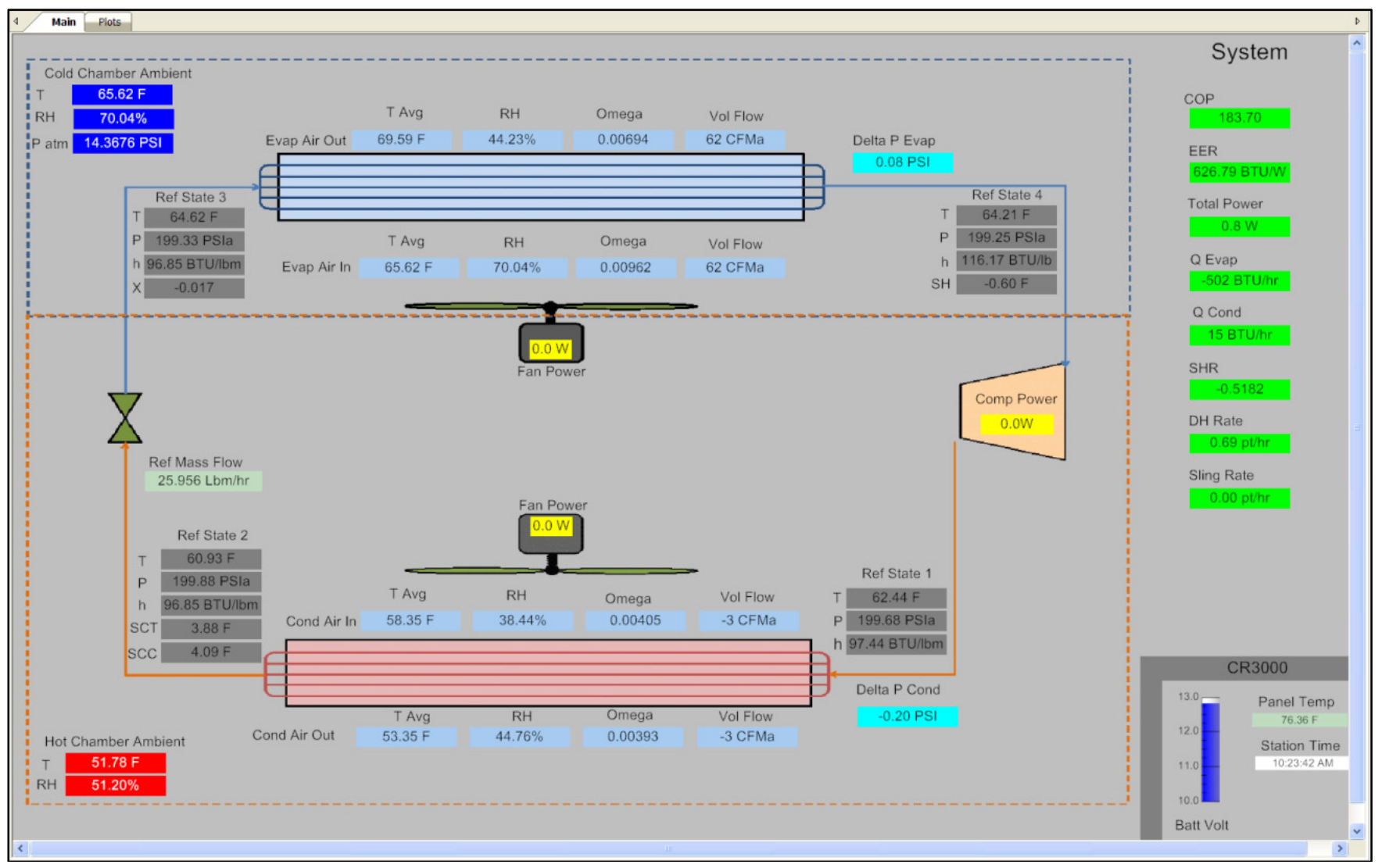

Figure 7: Screenshot of DAS system GUI 
Experimental uncertainty: To quantify the level of uncertainty in both the base measurements and the calculated quantities, a zero order analysis was performed. The study establishes overall uncertainties for various sensors at the standard test conditions. The analysis then tracks how these base uncertainties propagate through to the final calculated quantities (EER, COP, etc.). All data values were sampled at 1 second interval and were averaged over 30 minute. Some of the assumptions used in the analysis are given below-

(1) Uncertainties due to transient conditions are not considered since the tests focus on steady state analysis.

(2) Uncertainties introduced from linear interpolation of the refrigerant and saturated water vapor tables are considered negligible. Analysis of the data shows the linear approximation to be quite good over the small temperature/pressure increments used for the interpolation subroutines.

(3) The accuracy of any calculated value will be a function of both the ability to accurately measure the parameters used to calculate it as well as how accurately the equation models the actual physics of the process. The values presented in this study do not account for the latter.

(4) The results of the analysis presented here are for a single instantaneous measurement. Since many of the final results are based upon the average of $\mathrm{N}$ multiple measurements, the uncertainty in the average will decrease approximately by the factor of $\mathrm{N}^{-1 / 2}$, assuming that the sensor error is random in nature. Because of this, even in cases where the uncertainty for a single measurement is high (as is the case for the calculated condenser airflow), the average of 30 minutes of data is still a fair estimate of the average.

The results of the design point uncertainty analysis are reported in Table A1 of the Appendix.

\section{SALIENT EXPERIMENTAL DETAILS OF THE WINDOW UNIT}

In order to establish the baseline performance, the instrumented unit was first mounted in a plywood partition between the indoor and outdoor test chambers, as shown in Figure 6. The temperature and relative humidity of the indoor chamber were adjusted based upon the 
measurements at the evaporator air inlet. The outdoor chamber was adjusted based upon a single temperature/RH probe mounted a few feet from the intake louvers on the top of the unit. The outdoor and the indoor conditions inside the chamber were maintained at $\left[95^{\circ} \mathrm{F}\left(35^{\circ} \mathrm{C}\right)\right.$, $40.1 \% \mathrm{RH}]$ and $\left[80^{\circ} \mathrm{F}\left(26.7^{\circ} \mathrm{C}\right), 51.5 \% \mathrm{RH}\right]$ respectively.

Determination of Optimum Charge: Optimal refrigerant charge of R410A for the base unit was re-determined because of the increased volume of the system after the sensors were installed (see Figures 5 and 6). The system was initially filled with the factory charge and charge was then added in small increments to achieve the maximum EER at a superheat of around $4.4 \mathrm{~K}\left(=8^{0} \mathrm{~F}\right)$ at the standard rating conditions. As it can be seen from Figure 8 the level of superheat (left axis) and sub-cooling (right axis) would initially respectively decrease and increase substantially with the incremental charge but superheat eventually becomes asymptotic with subsequent additions at refrigerant charge above the 790 gm level. The corresponding EER and the system capacity are plotted in Figure 9, where the charge level of $790 \mathrm{gm}$, prior to the asymptotic behaviour, was considered optimum because the EER did not increase appreciably for greater charge levels.

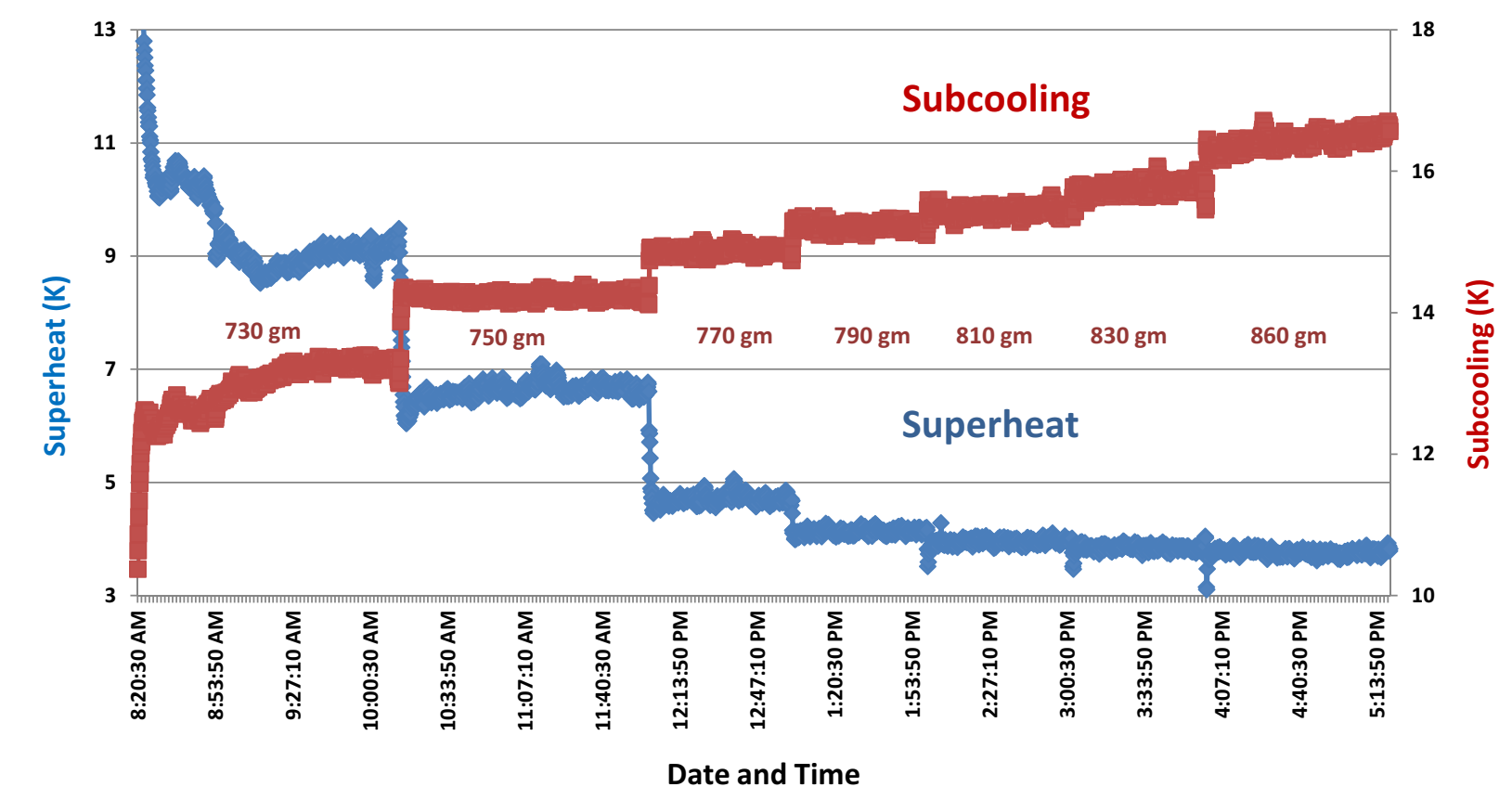

Figure 8: Variation of superheat and sub-cooling with refrigerant charge 


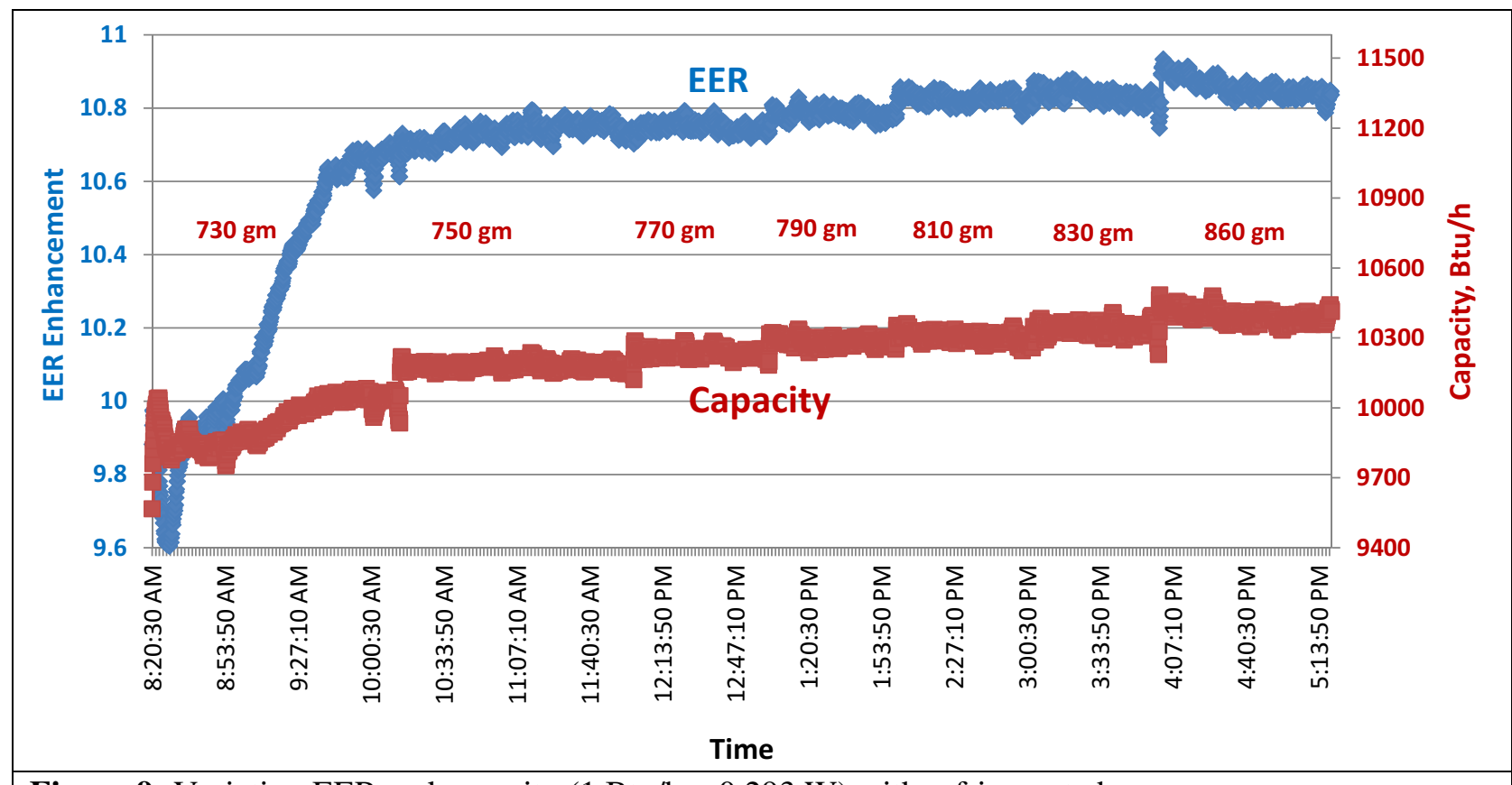

Figure 9: Variation EER and capacity $(1 \mathrm{Btu} / \mathrm{h}=0.293 \mathrm{~W})$ with refrigerant charge

With the unit installed in the chamber and charged, a test procedure was developed to generate the data as follows. With the unit running, bring both chambers to near the desired set points.

(1) Fine tune the chamber set points to achieve the desired inlet conditions as measured at the evaporator inlet sensors for the indoor chamber and the single temp/RH probe near the intake louvers on the outdoor chamber. The sensor uncertainty in the measurement of temperature and $\mathrm{RH}$ of the chamber was respectively $0.1^{\circ} \mathrm{C}$ and $1.4 \%$.

(2) When steady temperature/RH readings are achieved, allow at least $1 / 2$ hour for the window unit to achieve equilibrium. This allows time for the condensate level in the pan to reach a steady value. The capacity and total electrical power measurements should be steady within $\pm 2 \%$ of the mean value before testing begins. Allowing $1 / 2$ hour after any changes was found to achieve this condition.

(3) Once steady state is achieved, data is collected for an additional $1 / 2$ hour period.

Performance comparison with the rated baseline case: The WAC was tested in the environmental chamber as per the standard rating conditions noted above [DOE (2011)]. In general, the experimental results were found to correlate well with the published numbers, with 
differences of $-3 \%$ and $+2.6 \%$ for the experimental values of EER and capacity respectively, as shown in Table 1.

Table 1: Comparison of experimental values to rated performance

\begin{tabular}{|l|c|c|c|c|}
\hline \multicolumn{4}{|c|}{ Outdoor $=\mathbf{~ 9 5}^{\circ} \mathbf{F}, \mathbf{4 0 . 1 \%}$ RH } & \multicolumn{3}{c|}{ Indoor $=\mathbf{8 0}^{\circ} \mathbf{F}, \mathbf{5 1 . 5 \%}$ RH } \\
\hline & $\begin{array}{c}\text { EER } \\
(B t u / W h)\end{array}$ & $\begin{array}{c}\text { Capacity } \\
(\text { Btu/h) }\end{array}$ & $\begin{array}{c}\text { Evaporator } \\
\text { Airflow } \\
(\text { CFM })\end{array}$ & $\begin{array}{c}\text { Condenser } \\
\text { Airflow (CFM) }\end{array}$ \\
\hline Rated & 10.8 & 10,000 & 300 & 500 \\
\hline Experimental & 10.48 & 10,261 & 296 & 497 \\
\hline Difference & $-3.0 \%$ & $+2.6 \%$ & $-1.4 \%$ & $-0.6 \%$ \\
\hline
\end{tabular}

\# Air flow rate in cubic feet per minute $(1 \mathrm{CFM}=0.472 \mathrm{l} / \mathrm{s}) ; 1 \mathrm{BTU} / \mathrm{h}=0.293 \mathrm{~W}$;

Performance enhancement with "slinger" effect: In order to assess the effect of "slinger" on the performance of the window air-conditioner (WAC), a hole was drilled at the bottom of the WAC in the condenser pan that allowed the condensed water to be collected in a bucket and eliminate any entrained water from blowing over the condenser. The system was run at the standard test conditions and was allowed to reach steady state. The system EER was found to decrease by approximately $8 \%$ compared to the baseline data. No noticeable change was observed in the fan power. The condensate production rate, collected in the bucket, was measured to be about 1 liter/h.

\section{FEATURES TO ENHANCE EFFICIENCY OF A WINDOW AIR CONDITIONER}

Several efficiency enhancement options were considered in order to improve the WAC efficiency, including the following-

(1) Use of micro-channel heat exchangers (MCHXs)

(2) Reducing thermal bridging and internal air leakage through the divider wall

(3) Use of high EER compressor with lower rated capacity

(4) Use of an ECM (or brushless DC) fan motor in place of AC induction fan motor

(5) Reduce unit capacity from $10,000 \mathrm{Btu} / \mathrm{h}$ (or $2.93 \mathrm{~kW}$ ) to $8000 \mathrm{Btu} / \mathrm{h}$ (or $2.3 \mathrm{~kW}$ ) by downsizing its compressor

(6) Increase the molar concentration of R32 (from $70 \%$ to $85 \%$ ) in R410A 
MCHX: MCHXs are known to offer a higher volumetric heat capacity and a reduced refrigerant charge that may result in higher efficiency, particularly, in large capacity systems. This was the case when Yun et al. (2006) replaced the fin-and-tube condenser of a $7 \mathrm{~kW}$ cooling capacity residential air conditioner with a MC condenser. The COP of the system increased by up to $10 \%$. However, when Kim and Bullard (2002) replaced the fin-and-tube condenser of a WAC (of 4.1 $\mathrm{kW}$ cooling capacity as opposed to $2.93 \mathrm{~kW}$ of the current system), both the capacity and EER of the new WAC were lower than the baseline system. Since the current designs of MCHXs use lower fin density (e.g. 16 fins per inch on evaporator) while the chassis of the WAC has fixed dimensions and the capacity of the WAC is quite low $(=2.93 \mathrm{~kW})$, it is difficult to match the face area of the round tube plate fin coils with that of the micro-channel. Although MCHXs offer better performance in most HVAC\&R applications, they are not as deep as the copper tube heat exchangers and therefore, offer inferior performance (i.e. higher pressure drops, lower refrigeration capacity and less EER) than the round tube plate fin coils heat exchanger in a WAC. Therefore, this feature was found to be impractical to improve the efficiency of the current lower capacity WAC.

Reducing thermal bridging and internal air leakage: Although some of the low efficiency units may suffer from thermal bridging and internal air leakage through the divider wall, the unit under investigation was well engineered and had hardly any room for improving either the thermal bridging or the internal air leakage through the divider wall.

Testing the WAC with other high efficiency novel features: In order to assess the impact of the remaining efficiency improvement measures listed above, these were embedded into the WAC one-by-one to assess their individual performance. These were then integrated together into the unit to assess their overall impact on the performance of the WAC.

ECM Fan Motor- The first modification was the replacement of the baseline alternating current (AC) induction motor with a permanent magnet ECM. The factory AC motor was a permanent split capacitor type with a rated output of $95 \mathrm{~W}$. During the baseline tests, the motor was found to consume 177W, 158W and 137W at the high (1343 RPM), medium (1256 RPM), and low (1150 RPM) fan speeds respectively. The replacement motor was a sensor-less ECM with rated 100W mechanical output. The system was charged to the same level as the baseline case and the test chambers were run at the standard testing conditions noted previously. The ECM fan motor was 
then run at the same RPM as the high and low settings of the baseline fan. Data was collected at 5s intervals for 30 minutes at each speed and 30 minutes was allocated for the system to stabilize after the RPM was changed. Figure 10 shows a significant increase of more than $8 \%$ in system EER (= 11.7 compared with 10.8 of baseline) through this change alone. The use of higher efficiency ECM brushless fan motor offers essentially twofold benefits. Not only is less energy used to produce the same airflow, less heat is being dissipated in the chassis resulting in lower temperature of the condenser inlet air.

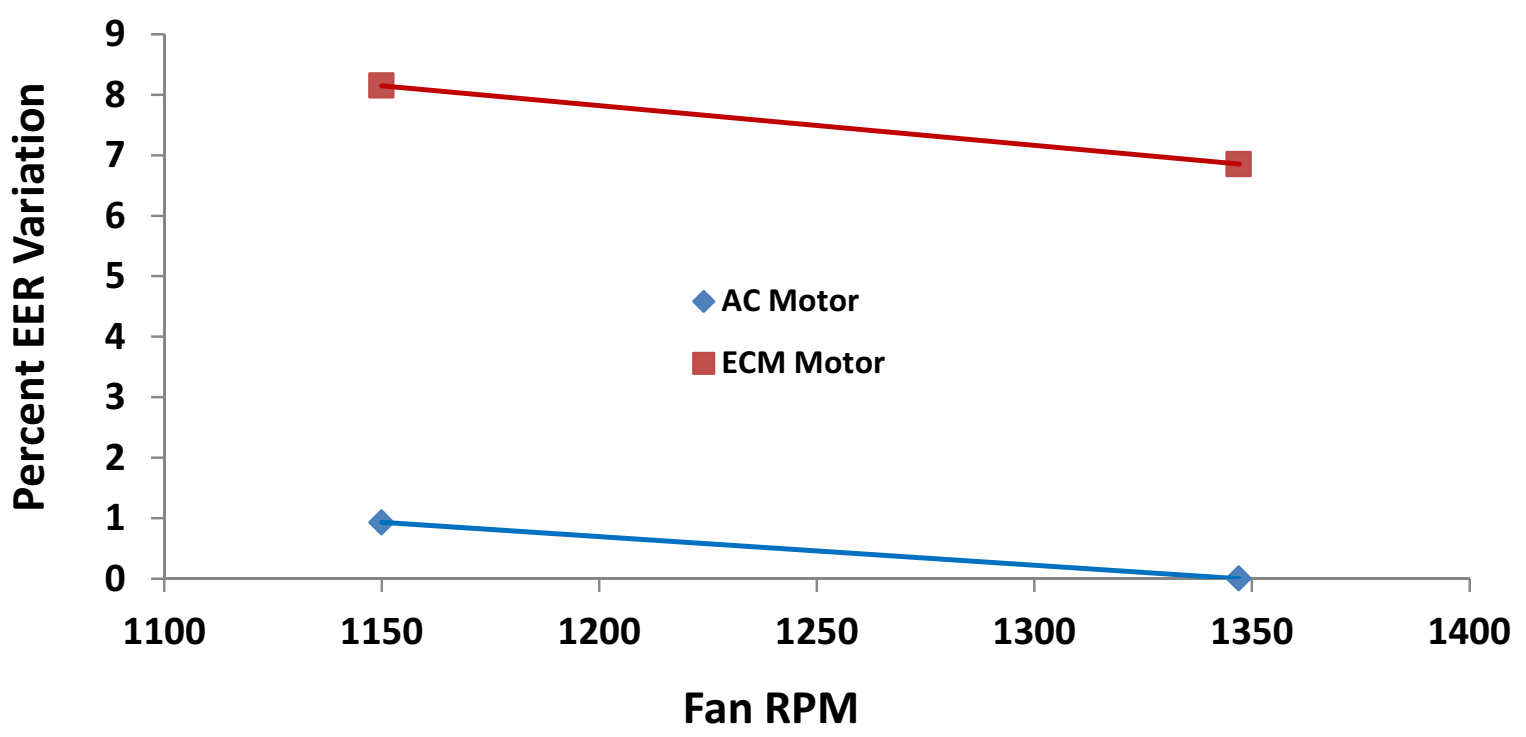

Figure 10: Variation of EER with fan speed for baseline unit and unit with ECM Fan

System Capacity Reduction- In an attempt to further increase system efficiency, the baseline $10,000 \mathrm{Btu} / \mathrm{h}(=2.93 \mathrm{~kW})$ compressor was replaced with one rated at 8,000 Btu/h $(2.3 \mathrm{~kW})$. The baseline heat exchangers were retained and because they are essentially oversized for the derated unit, the system can be run at a lower pressure ratio than the original baseline WAC. To optimally control this, the capillary tube on the baseline unit was replaced with a fine adjust needle valve. A sight glass was also added at the compressor suction of the system to avoid liquid slugging of the compressor by inadvertently opening the valve too far. Because the system volume is changed by the integration of the smaller compressor, the charge optimization study was re-performed, while maintaining the superheat closer to $4.4 \mathrm{~K}\left(8^{\circ} \mathrm{F}\right)$. Figure 11 shows the variation of modified system EER and its capacity with charge, where a maximum EER 
improvement of $6.2 \%$ (at a capacity of $8626 \mathrm{Btu} / \mathrm{h}$ ) was achieved at a charge level of $680 \mathrm{gm}$ over the baseline case.

System Capacity Reduction and ECM Fan Motor- With the incremental improvement from the smaller compressor quantified, the same reduced capacity system was tested with the ECM fan motor. The unit was charged with $680 \mathrm{gm}$ and the airflow was varied between 1050 and 1400 RPM, again with time allocated for the unit to stabilize between changes. The needle valve was adjusted at each airflow rate to maintain suction superheat at about $4.4 \mathrm{~K}\left(=8.0^{\circ} \mathrm{F}\right)$. Figure 12 shows the variation of system EER and fan power input with fan RPM. The test data is fit with a $2^{\text {nd }}$ order polynomial which predicts a maximum EER improvement of $18.2 \%$ over the baseline case (i.e. EER enhancement from 10.8 to 12.77) at a fan speed of about 1210 RPM. The corresponding unit capacity and fan power input were respectively 8,310 Btu/h and $79 \mathrm{~W}$.

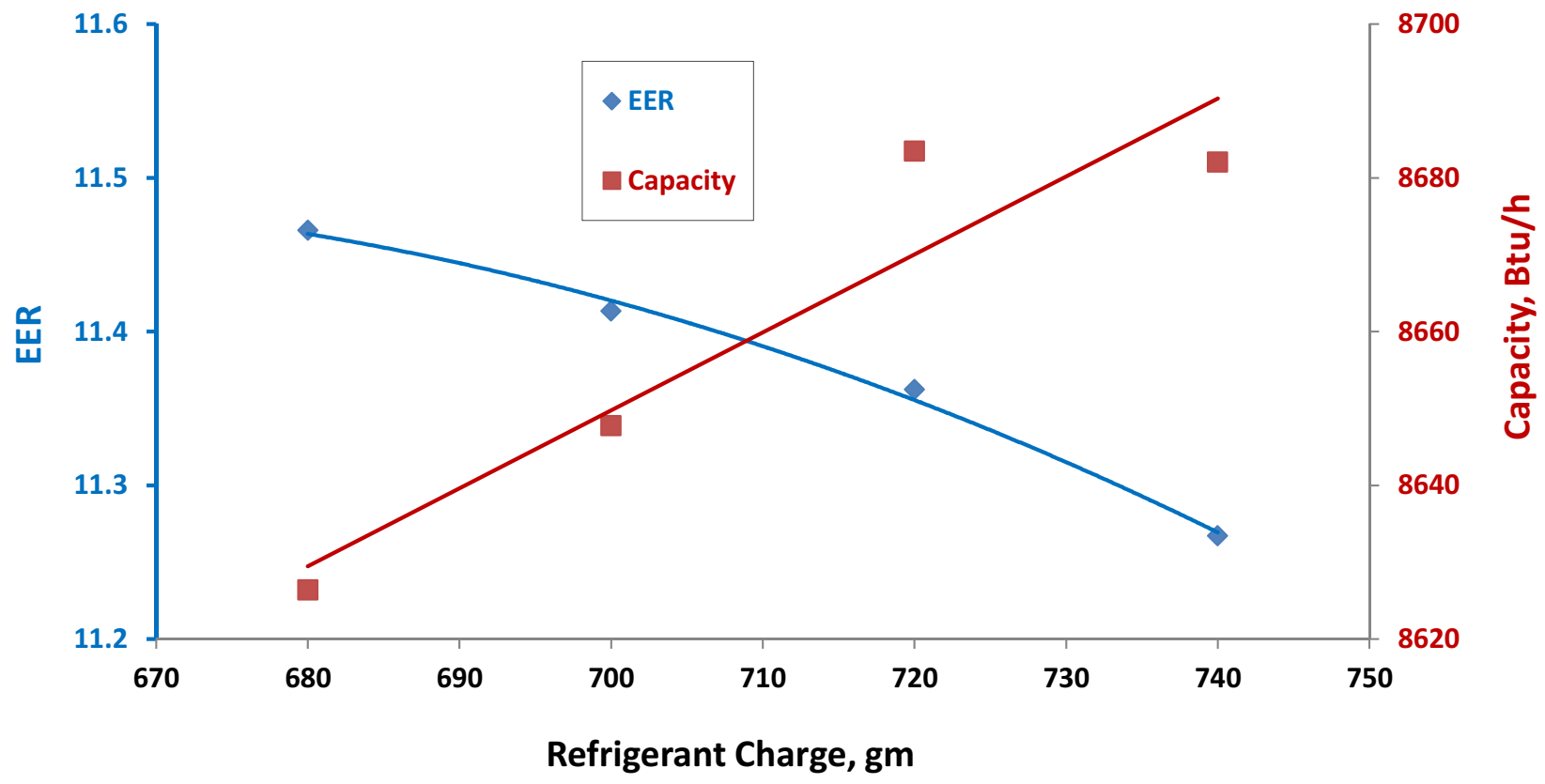

Figure 11: Variation of EER with Charge for the reduced system capacity 


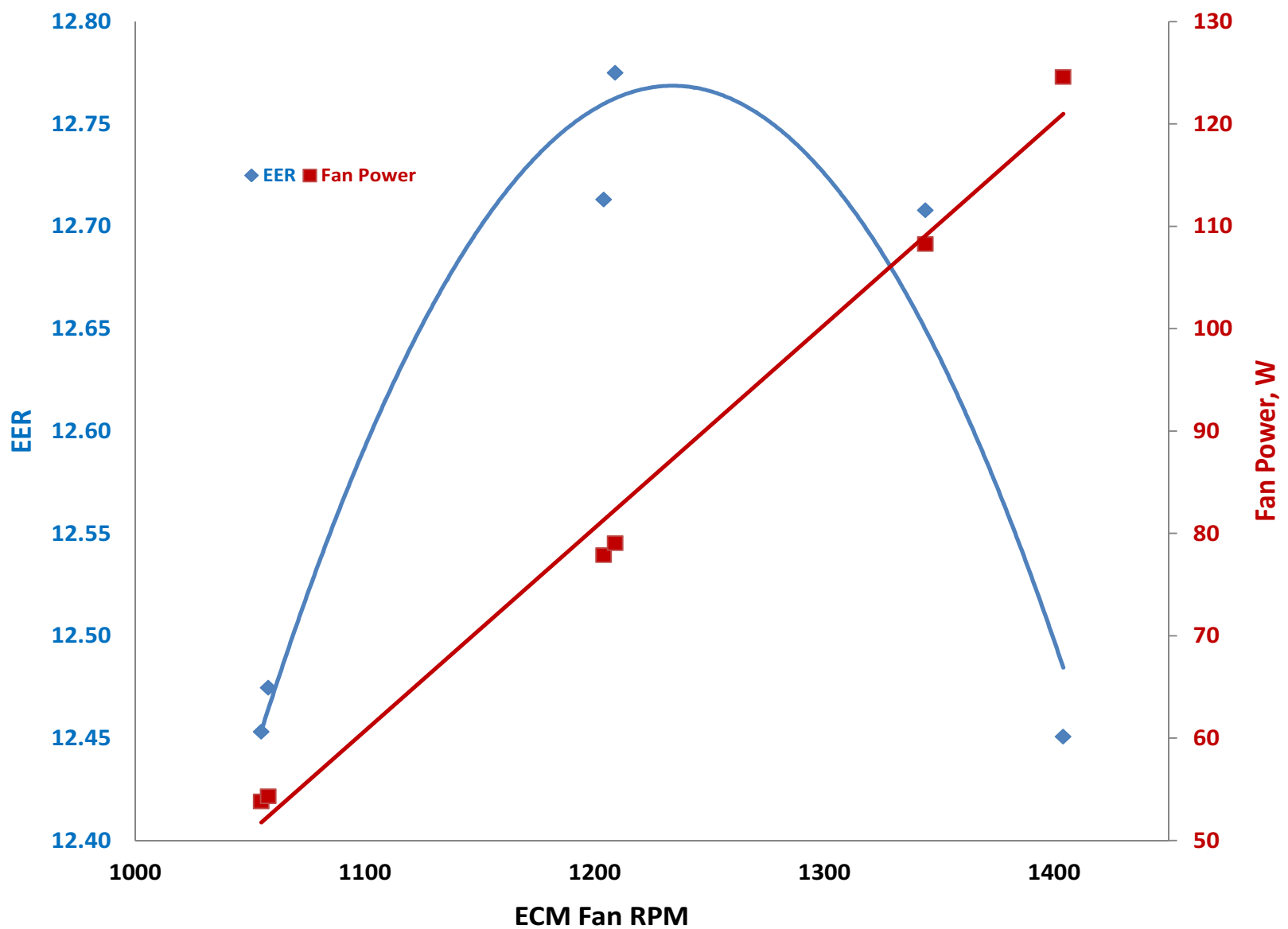

Figure 12: Variation of EER and fan power input for the reduced capacity system with RPM of ECM Fan

\section{System Capacity Reduction, ECM Fan Motor and 85\% molar concentration of R32-}

$\mathrm{R} 410 \mathrm{~A}$ is a 70/30\% (by mole) mixture of R32 and R125. An increase in the concentration of R32 leads to increased system capacity for a given mass flow rate at the expense of the mixture becoming slightly flammable. To explore the effects of the higher R32 concentration, the unit was evacuated and charged with an $85 / 15$ molar mix of the two refrigerants. Due to time constraints, this test was run only with the $8,000 \mathrm{Btu} / \mathrm{h}$ (or $2.3 \mathrm{~kW}$ ) compressor (shown by $8 \mathrm{~K}$ Comp in Figure 14) and ECM fan instead of starting with the baseline compressor and AC fan motor. As before, a charge study was conducted with the optimum charge being found to be 620 gm. Although tests were run at two airflow rates with varying degrees of suction superheat, results are shown only for fan RPM of 1154 (due to brevity of space) in Figure 13. As shown, a maximum EER improvement of $21.3 \%$ (i.e. EER enhancement from baseline 10.8 to 13.1 ) was measured over the baseline unit at a superheat of around $4.8 \mathrm{~K}\left(8.6^{\circ} \mathrm{F}\right)$. The corresponding capacity and the compressor discharge temperature were respectively $8,428 \mathrm{Btu} / \mathrm{h}$ and $51.9^{\circ} \mathrm{C}$. It 
may be noted that the custom blend improved the EER over R410A by about 3\%, which is in agreement with the modelling results of Bansal and Shen (2015).

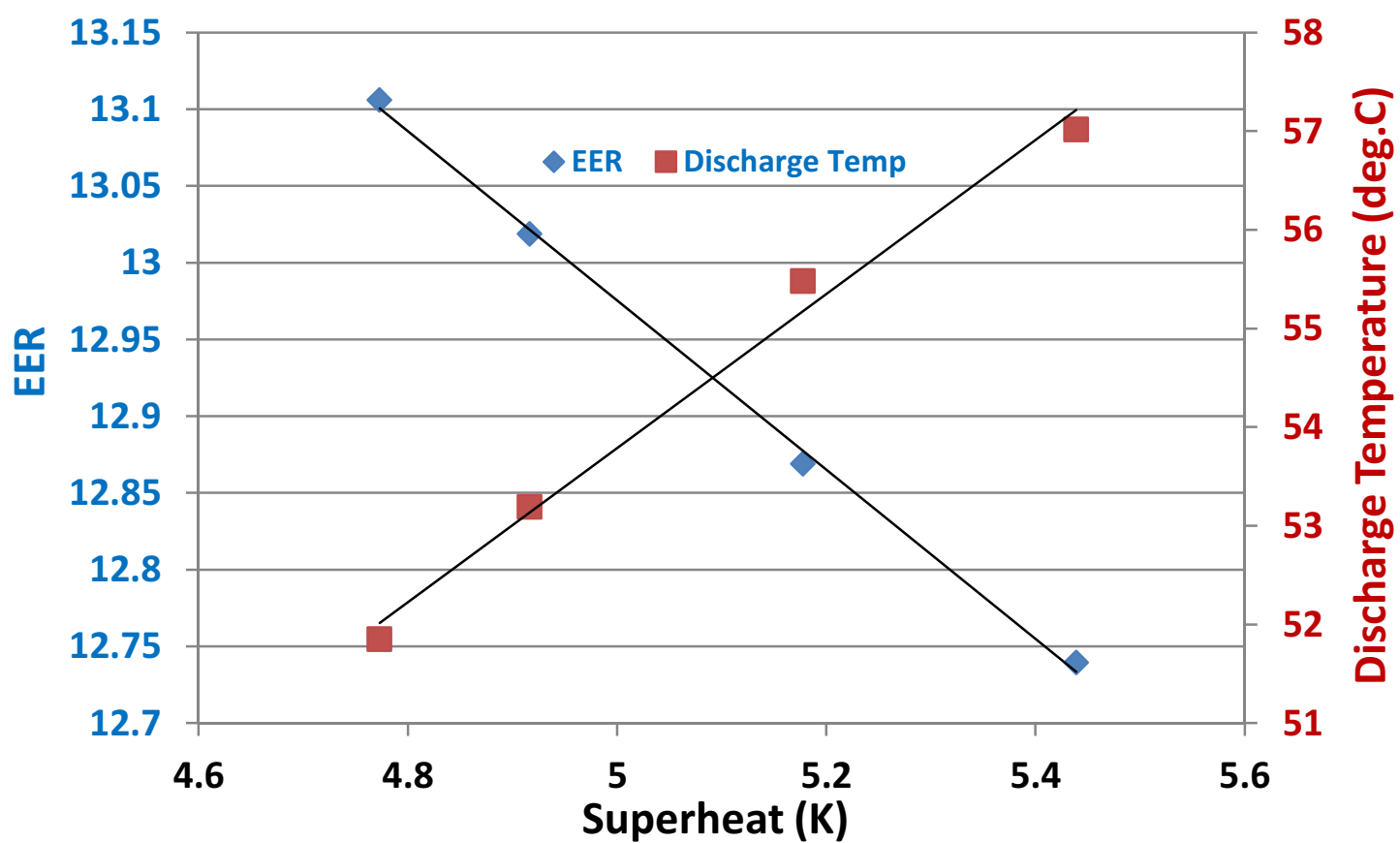

Figure 13: Variation of Efficiency Enhancement vs. Superheat, with ECM Fan (at 1154 RPM) and R32/R125 (85/15) Mixture

Overall Summary and Discussion- Table 2 summarizes the tests conducted and the percent improvement of each over the baseline performance. Figure 14 displays the incremental EER enhancements and the corresponding system capacity for each option from the baseline unit to the mixture of R32 ( $85 \%$ by mole) and R125 (15\% by mole).

Table 2: Summary of Test Results

\begin{tabular}{|l|c|c|c|c|}
\hline \multicolumn{1}{|c|}{ Tests } & ECM Fan & $\begin{array}{c}\text { Reduced } \\
\text { Capacity }\end{array}$ & $\begin{array}{c}\text { Increase of R32 } \\
\text { molar concentration } \\
\text { to 85\% }\end{array}$ & $\begin{array}{c}\text { Percent EER } \\
\text { Increase over } \\
\text { baseline unit }\end{array}$ \\
\hline Baseline & no & no & no & $0 \%$ \\
\hline Test 1 & yes & no & no & $8.1 \%$ \\
\hline Test 2 & no & yes & no & $6.2 \%$ \\
\hline Test 3 & yes & yes & no & $18.2 \%$ \\
\hline Test 4 & yes & yes & yes & $21.3 \%$ \\
\hline
\end{tabular}




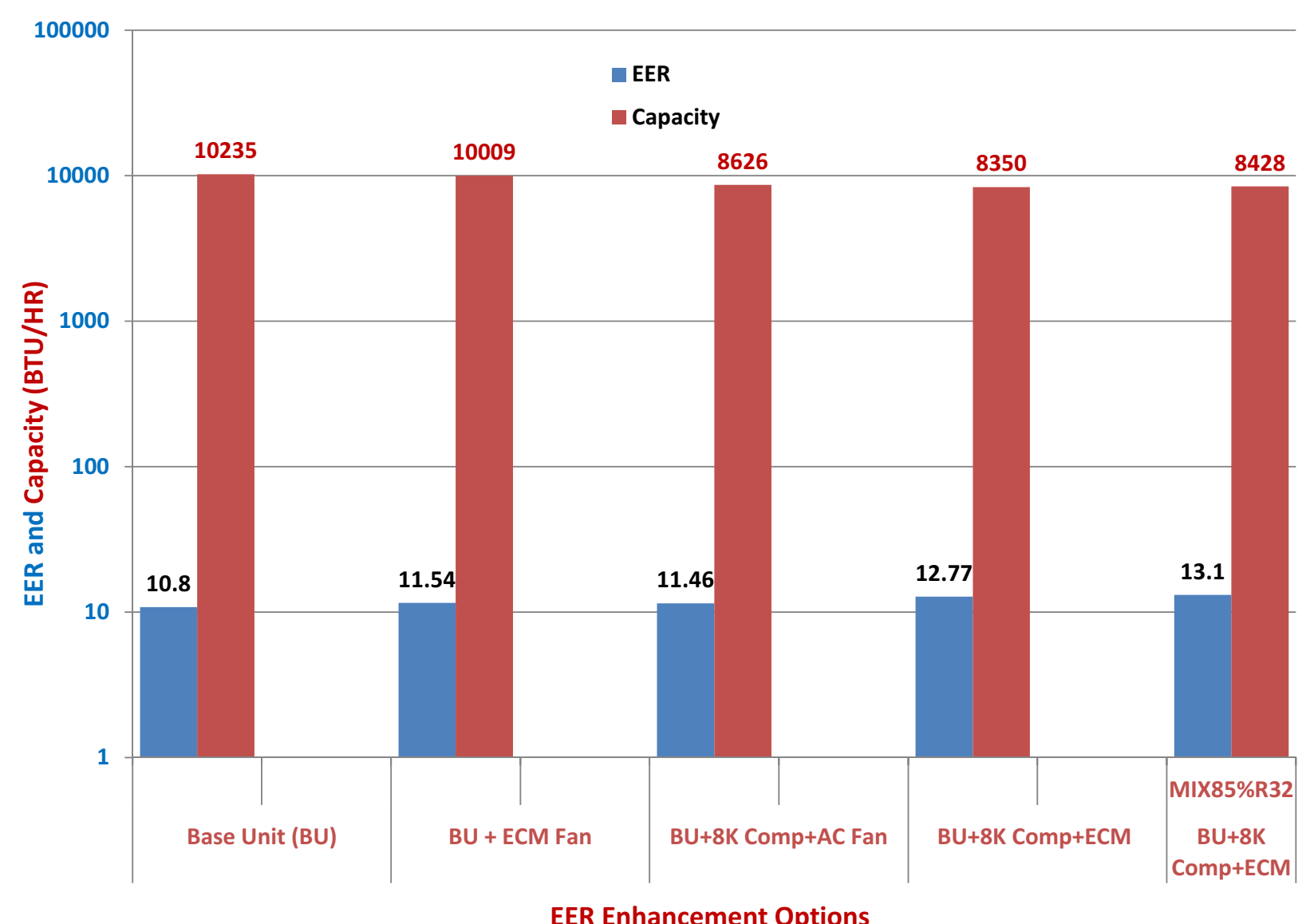

Figure 14: Incremental enhancement in EER along with the corresponding system capacity $(1 \mathrm{Btu} / \mathrm{h}=$ $0.293 \mathrm{~W}$ ) with different options; [8K Comp $-8,000 \mathrm{Btu} / \mathrm{h}$ capacity compressor]

Each of the modifications tested here under laboratory conditions, comes with its own incremental cost and engineering challenges with regards to the eventual goal of producing a marketable, higher-efficiency WAC. The ECM fan motor was found to be a major improvement over the alternating current induction motor both for its main effect of using less power as well as the secondary effect of not dumping as much heat into the condenser section of the unit. From an engineering perspective, the integration of the ECM was straightforward as the dimensions of the motor used were well matched to the existing shroud assembly. For the cases tested, the increase in the R32 concentration of the refrigerant was found to give an incremental improvement over the standard R410A mixture. This blended mixture of R32/R125 has about a $34 \%$ lower GWP compared to R410A (1,377 vs. 2,079). The new design offers the technical potential of 0.1 quads of energy savings per year in USA alone and significantly more in other countries where WACs are used more widely such as in Asia, Africa and Middle East [Bansal 
(2015)]. This results in a number of additional advantages including the reduction in its operating cost, electrical demand, and the environmental impact.

Economic Analysis and Payback Period: As per DOE standard [e-CRF Part 430.32 (2010)], the minimum energy efficiency ratio (EER) of a base window air conditioner (WAC) having $8,000 \mathrm{Btu} / \mathrm{h}$ (or $2.3 \mathrm{~kW}$ ) capacity is $9.7 \mathrm{Btu} / \mathrm{Wh}$, while the EER of an improved unit would be 13.1, as demonstrated in this study. Further, as per DOE standard [e-CFR Part 430.23 (2010)], the normal operation time $(\Delta t)$ of a WAC is expected to be 750 hours per year. Therefore the yearly energy savings from the use of the more efficient WAC will be -

Energy Savings $=\left[\left(\frac{\text { Unit Capacity }\left(\frac{B t u}{h}\right)}{\text { EER-base }\left(\frac{B t u}{W h}\right)}\right)-\left(\frac{\text { Unit Capacity }\left(\frac{B t u}{h}\right)}{\text { EER-efficient }\left(\frac{B t u}{W h}\right)}\right)\right] * \Delta t=160.5 \mathrm{kWh}$

According to the US Energy Information Administration's latest data the national average price of residential electricity (\$E) in the USA is $\$ 0.1224 / \mathrm{kWh}$ (USEIA 2015). For this electricity cost the total annual savings per year for the improved WAC will be,

Savings= Energy savings $(k W h) * \$ E=\$ 19.65$ per year

Since the chassis, heat exchangers and other components of the larger $10,000 \mathrm{Btu} / \mathrm{h}$ (or $2.93 \mathrm{~kW}$ ) baseline WAC were used in this study, the retail cost difference between an 8,000 Btu/h (or 2.3 $\mathrm{kW}$ ) and a 10,000 Btu/h (or $2.93 \mathrm{~kW}$ ) WAC is about $\$ 20$, based on material and component weight [GEA (2015)]. The cost premium of an efficient 8,000 Btu/h capacity compressor over a larger 10,000 Btu/h capacity compressor would be almost negligible, and so would be the cost of the new refrigerant mixture over R410A due to small charge. The only other expense would be the replacement of an alternating current motor with a more efficient brushless ECM fan motor. This is projected to be about $\$ 8$ [GEA (2015)]. Therefore, the total additional cost of the new efficient WAC is $\$ 28$ against the savings of $\$ 19.65$ per year. This translates to a payback period of 1.42 years over the expected life time of 20 years of a WAC. This payback period of the modified energy efficient WAC is very encouraging and should appeal to the industry. 


\section{CONCLUSIONS}

This paper presented the design and development details of a high efficiency WAC. A number of novel features were evaluated in the study including an ECM fan, a high efficiency compressor, large heat exchangers of the base unit and a 'drop-in' refrigerant mixture of R32/R125 (85\%/15\% molar concentrations). The use of the ECM fan motor alone in the baseline unit led to 8\% EER improvement. This, when complimented with the high efficiency (but less capacity) compressor, led the EER to improve by $18.2 \%$. Finally, the combination of the ECM fan motor, high efficiency compressor and the blend of R32/R125 (85/15 molar concentrations) enhanced the system EER by $21.3 \%$. The new design offers the technical potential of 0.1 quads of energy savings per year in USA alone and significantly more in other countries where WACs are used more widely such as in Asia, Africa and Middle East. The economic analysis revealed the payback period of about 1.4 years of the modified energy efficient WAC, which is rather encouraging, particularly, for the 20 year life span of a WAC. The potential improvement in WAC efficiency demonstrated an exemplary approach that would lead to considerable efficiency and environmental advantages, and its usefulness to the society.

\section{ACKNOWLEDGMENTS}

The author is thankful to the Building Technologies Office of the US Department of Energy for their financial support and industry partner General Electric Appliances for their in-kind and technical support. Special thanks are due to a number of contributors for their invaluable contributions and support during this project, including Mr. Edward Vineyard, Mr. Van Baxter, Dr. Chris Halford, Dr. Bo Shen, Mr. Brice Bowley, Mr. Charles Smith, Mr. Jiancheng Zong, Mr. Paul Lin, Mr. Mark Hoehne, Dr. Keith Rice, Mr. Randall Linkous, Mr. Neal Durfee, Mr. Geoff Ormston and Mr. Brian Goins.

Nomenclature
\begin{tabular}{|l|l|l|l|}
\hline $\begin{array}{l}\text { BU- baseline unit } \\
\begin{array}{l}\text { COP- Coefficient of } \\
\text { performance }\end{array}\end{array}$ & $\begin{array}{l}\text { E: Energy; } \\
\$ E: \text { Price of residential } \\
\text { electricity, } \$ / \mathrm{kWh}\end{array}$ & $\begin{array}{l}\text { EER: Energy Efficiency } \\
\text { Ratio }\end{array}$ & $\begin{array}{l}\text { ECM: Electronically } \\
\text { commutated motor }\end{array}$ \\
\hline h: Enthalpy $(\mathrm{Btu} / \mathrm{lb}$ or kJ/kg) & $\dot{m}=$ Flow Rate $(\mathrm{lb} / \mathrm{h}$ or kg/s) & P: Pressure (psia or kPa) & RH: Relative humidity \\
\hline $\begin{array}{l}\text { q: Capacity }(\mathrm{Btu} / \mathrm{h} \text { or W) } \\
\text { T: Temperature }\left({ }^{\circ} \mathrm{F} \text { or }{ }^{\circ} \mathrm{C}\right)\end{array}$ & $\begin{array}{l}\Delta \mathrm{t}: \text { Time of operation of a } \\
\text { WAC per year, hours/year }\end{array}$ & $\begin{array}{l}\text { WAC: Window air } \\
\text { conditioner }\end{array}$ & x: quality \\
\hline Subscripts: & c: condenser & e: evaporator & f: liquid \\
\hline g: vapor & SH: Superheat & SC: Sub-cooling & sat: Saturation \\
\hline com: Compressor & t: Total & & \\
\hline
\end{tabular}




\section{REFERENCES}

Bansal, P., 2015, High efficiency room air conditioner, DOE report, ORNL/TM-2015/10

Bansal, P. K. and Shen, B., 2015, Analysis of environmentally friendly refrigerant options for window air conditioners, J. Science and Technology for the Built Environment, In Press.

Bolaji, B. O., 2011, Performance investigation of ozone-friendly R404A and R507 refrigerants as alternatives to R22 in a window air-conditioner, Energy and Buildings, 43, pp 3139-3143.

Chua, K. J., Chou, S. K., Yang, W. M. and Yan, J., 2013, Achieving better energy-efficient air conditioning - A review of technologies and strategies, Applied Energy, 104, pp 87-104.

Devotta, S., Padalkar, A. S. and Sane, N. K., 2005, Performance assessment of HC-290 as a drop-in substitute to HCFC-22 in a window air conditioner, International J Refrigeration, 28, pp 594-604.

DOE, 2011, "Residential Clothes Dryers and Room Air Conditioners Direct Final Rule Technical Support Document", 4/18/2011; updated on 03/02/2012, http://www1.eere.energy.gov/buildings/appliance_standards/residential/residential_clothes_dryers_ro om_ac_direct_final_rule_tsd.html

e-CFR Title 10: "Energy, Part 430.32- Energy conservation program for consumer products", 2014, http://www.ecfr.gov/cgi-bin/textidx?SID=19211021fb068617aba13063da4e959a\&node=10:3.0.1.4.18.3.9.2\&rgn=div8

e-CFR Title 10: "Energy, Part 430.32- Energy conservation program for consumer products", 2010, http://www.ecfr.gov/cgi-bin/textidx?SID=19211021fb068617aba13063da4e959a\&node=10:3.0.1.4.18.3.9.2\&rgn=div8

e-CFR Title 10: "Energy, Part 430.23- Test procedures for the measurement of energy and water consumption", 2010, http://www.ecfr.gov/cgi-

$\mathrm{bin} /$ retrieveECFR?gp=\&SID=990420523de9b56348a303e7115d9a7b\&mc=true \&n=pt10.3.430\&r=PART $\&$ ty=HTML\#se10.3.430_123

EIA (2009); Residential Energy Consumption Survey, US DOE Energy Information Administration, http://www.eia.gov/consumption/residential/data/2009/

GIA 2015, General Electric Appliances, Cost estimates of various components and related features of window air-conditioners, private communication, April 2015.

Goswami, D.Y., Mathur, G. D. and Kulkarni, S. M., 1993, Experimental investigation of performance of a residential air conditioning system with an evaporatively cooled condenser, Journal of Solar Energy Engineering 115, 206-211.

Hajidavalloo, E., 2007, Application of evaporative cooling on the condenser of window-air-conditioner, Applied Thermal Engineering, 27, pp 1937-1943.

Jabaraj, D.B., Avinash, P., Mohan Lal, D. and Renganarayan, S., 2006, Experimental investigation of HFC407C/HC290/HC600a mixture in a window air conditioner, Energy Conversion and Management, 47, pp 2578-2590

Kim, M-H. and Bullard, C. W., 2002, Performance evaluation of a window room air conditioner with microchannel condensers, J. Energy Resources Technology (ASME), Vol. 124, pp 47-55.

Meissner, J. W., Abadie, M. O., Moura, L. M., Mendonca, K. C. and Mendes, N., 2014, Performance curves of room air conditioners for building energy simulation tools, Applied Energy, 129, pp 243252.

Naphon, P. 2010, On the performance of air conditioner with heat pipe for cooling air in the condenser, Energy Conversion and Management, 51, pp 2362-2366. 
Lawrence Livermore National Laboratory (LBNL), 1997, “Technical support document for energy conservation standards for room air conditioners: Volume 2 - Detailed analysis of efficiency levels", Docket Numbers EE-RM-90-201 \& EE-RM-93-801-RAC, September.

Nogueira, L A H, 2013, "Package of measures to promote efficient air conditioning", ADEME, World Energy Council Study, http://www.wec-policies.enerdata.eu/Documents/casesstudies/Measures_to_promote_efficient_air_conditioning.pdf

Sawant, A. P., Agrawal, N. and Nanda, P, 2012, Performance assessment of an evaporative coolingassisted window air conditioner, International J low-carbon technologies, 7, pp 128-136.

Shen, B. and P. K. Bansal, 2014, Assessment of environmentally friendly refrigerants for window air conditioners, ID2275, Proc. $15^{\text {th }}$ International Refrigeration and Air Conditioning Conference, Purdue University, West Lafayette, July 14-17.

USEIA 2015, Electric Power Monthly: with Data for March 2015, Table 5.6B, http://www.eia.gov/electricity/monthly/pdf/epm.pdf, date accessed - June 5, 2015.

Winkler, J., C. Booten, D. Christensen and J. Tomerlin, 2013, Laboratory performance testing of residential window air conditioners, NREL/TP-5500, 57617, July.

Yun, R., Hwang, Y., Radermacher, R. and Zecirovic, R., 2006, Comparison of performance of a residential air-conditioner system using microchannel and fin-and-tube heat exchanger, R108, 8 pages, Proc. $11^{\text {th }}$ International Refrigeration and Air conditioning conference, Purdue University, West Lafayette, July 17-20.

Zhou, G. and Zhang, Y., 2010, Performance of a split-type air conditioner matched with coiled adiabatic capillary tubes using HCFC22 and HC 290, Applied Energy, 87(5), pp 1522-1528. 


\section{APPENDIX A}

Table A1: Results of the design point uncertainty analysis

\begin{tabular}{|l|c|}
\hline \multicolumn{2}{|c|}{ Base Measurements } \\
\hline Measurement & Estimated Combined Logger and Sensor Uncertainty \\
\hline Temperature & $\pm 0.1^{\circ} \mathrm{C}$ \\
\hline Refrigerant Pressure (low) & $\pm 1.3 \mathrm{kPa}$ \\
\hline Refrigerant Pressure (high) & $\pm 4.1 \mathrm{kPa}$ \\
\hline Mass Flow Rate & $\pm 0.1 \mathrm{~g} / \mathrm{s}$ \\
\hline Electrical Power (fan) & $\pm 2 \mathrm{~W}$ \\
\hline Electrical Power (compressor and system total) & $\pm 10 \mathrm{~W}$ \\
\hline Atmospheric Pressure & $\pm 0.06 \mathrm{kPa}$ \\
\hline Relative Humidity & $\pm 1.4 \% \mathrm{RH}$ \\
\hline \multicolumn{2}{|c|}{ Calculated Values } \\
\hline \multicolumn{2}{|c|}{} \\
\hline Parameter & Estimated Uncertainty \\
\hline EER & $\pm .12 \mathrm{Btu} / \mathrm{Wh}$ \\
\hline System Capacity & $\pm 16.7 \mathrm{~W}$ (or $\pm 57 \mathrm{Btu} / \mathrm{h})$ \\
\hline Condenser Heat Transfer Rate & $\pm 18.2 \mathrm{~W}($ or $\pm 62 \mathrm{Btu} / \mathrm{h})$ \\
\hline State 5 Quality & \pm 0.002 \\
\hline State 1 Superheat & $\pm 0.16 \mathrm{~K}$ \\
\hline State 4 Subcool & $\pm 0.16 \mathrm{~K}$ \\
\hline Refrigerant Evaporator Pressure Drop & $\pm 2 \mathrm{kPa}$ \\
\hline Refrigerant Condenser Pressure Drop & $\pm 5.5 \mathrm{kPa}$ \\
\hline Average Air Temperatures & $\pm 0.05 \mathrm{~K}$ \\
\hline
\end{tabular}

